\title{
BIOLOGICAL ACTIVITIES OF SANGUISORBA MINOR L. EXTRACTS - IN VITRO AND IN VIVO EVALUATIONS
}

\author{
TIJANA CIROVIC ${ }^{1}$, ANA BARJAKTAREVIC ${ }^{1 *}$, MILICA NINKOVIC ${ }^{2}$, \\ RUDOLF BAUER ${ }^{3}$, STEFANIE NIKLES ${ }^{3}$, SNEZANA BRANKOVIC $^{4}$, \\ MARIJA MARKOVIC 5 , VESNA STANKOV JOVANOVIC ${ }^{6}$, MARIJA ILIC ${ }^{6}$, \\ OLIVERA MILOVANOVIC ${ }^{1}, \mathrm{KSENIJA} \mathrm{KOJICIC}^{1}$, and SNEZANA CUPARA ${ }^{1}$
}

\author{
${ }^{1}$ Department of Pharmacy, Faculty of Medical Sciences, University of Kragujevac, Serbia \\ ${ }^{2}$ Institute of Medical Research, Military Medical Academy, Serbia \\ ${ }^{3}$ Institute of Pharmaceutical Sciences, University of Graz, Austria \\ ${ }^{4}$ Institute of Biology and Ecology, Faculty of Science, University of Kragujevac, Serbia \\ ${ }^{5}$ Department of Biology and Ecology, Faculty of Science and Mathematics, \\ ${ }^{6}$ Department of Chemistry, Faculty of Science and Mathematics, \\ University of Nis, Serbia
}

\begin{abstract}
The literature data about Sanguisorba minor L. subsp. muricata Briq. (fam. Rosaceae) are limited. It has been used in folk medicine for its diuretic and digestive properties, or in the treatment of fever and diarrhea. The aim of the study was to evaluate the antioxidant, antimicrobial and anti-inflammatory potential of S. minor subsp. muricata root extracts (in vitro and in vivo). Methanol, ethanol and chloroform extracts were characterized by total phenolic and flavonoid content. Antioxidant activity was estimated by five different assays in vitro, and in vivo in the animal model of sepsis. Antimicrobial activity was tested against Gram-positive bacteria, Gram-negative bacteria and one fungus by micro-well dilution assay. Cyclooxygenase-1 inhibition assessment of S. minor ethanol extract was performed in the presence of Indomethacin. Ethanol and methanol extracts did not differ significantly in the content of phenols and flavonoids, as well as in achieved antioxidant activity. Both of these extracts were superior to the chloroform extract. Ethanol and methanol extracts showed similar antimicrobial activity. Chloroform extract exhibited strong activity against all examined strains of bacteria, but moderate against Candida albicans. Ethanol extract induced $76 \%$ inhibition of Cyclooxygenase- 1 in vitro. The same extract decreased the level of the oxidative stress parameters in an animal model of sepsis. All extracts exhibited considerable antimicrobial and antioxidant activities, while ethanol extract showed anti-inflammatory potential. Based on the effects achieved on oxidative stress parameters in sepsis, $S$. minor could be considered as a herbal adjuvant antioxidant therapy in systemic infectious treatment.
\end{abstract}

Keywords: Sanguisorba minor subsp. muricata, oxidative stress, antioxidant activity, antimicrobial activity, anti-inflammatory activity

Different species belonging to the genus Sanguisorba L., Rosaceae, have natural habitats in Europe and Asia. Sanguisorba minor L. subsp. muricata Briq. has been found as native in Serbia $(1,2)$. The research previously done was focused mainly on Sanguisorba officinalis L. species, while the information on S. minor (small burnet) species is scarce. There is a particular lack of data on $S$. minor muricata subspecies. The intention of this study was to characterize $S$. minor L. subsp. muricata Briq. more thoroughly. Studies on different parts of species $S$. minor confirmed the high content of polyphenols, $\beta$-carotene, vitamin $\mathrm{E}$, and vitamin $C$, which implied the potential for antioxidant activity (3). Several unique phenolic carboxylic acids, triterpenoids, tannins, and new flavonoids were isolated and identified from the aerial parts and root of $S$. minor (4-6). Although the complete information on chemical composition has been limited, the presence of phytoconstituents found in $S$. minor points to the possible antiinflammatory activity of extracts from different

\footnotetext{
* Corresponding author: e-mail: ana.radovanovickg@gmail.com
} 
parts of the plant - aqueous extract of $S$. minor subsp. muricata flowering aerial parts showed dose-dependent anti-inflammatory activity $(7,8)$. Species $S$. minor has been used in folk medicine, in the form of infusion or tincture, for its diuretic, digestive and appetite-stimulant properties, or as a fever and diarrhea treatment. The aerial parts of this species showed an anti-ulcerogenic effect, which is in accordance with data available for plants from Sanguisorba genus - they expressed in vitro and in vivo hemostatic, antibacterial, neuroprotective, or hypoglycemic effects $(9,10)$. Besides medicinal activities, young shoots, aerial parts and roots of $S$. minor are edible and usually consumed as mixed vegetable salads (11).

Sepsis is a systemic inflammatory response to severe body infections and may lead to overwhelming shock. If not treated promptly, it may produce finally death, causing multiple organ failure. Mechanisms of inflammation and cellular damage, such as the generation of cytokines and reactive oxygen species, have been involved in the pathogenesis of sepsis. Hypotension and inappropriate oxygen delivery to the tissue may be crucial in the developing pathogenesis of sepsis (12).

Considering the pathophysiological pathways in sepsis, the combination of conventional therapy and antioxidant therapy may decrease the severity of the disease or improve disease outcomes $(13,14)$. In spite of recent advances in therapy, sepsis remains the primary cause of mortality in hospital conditions (15). Therefore, antioxidant and anti-inflammatory responses of herbal extracts have been elucidated on different animal sepsis models $(16,17,18)$.

The aim of this paper was to evaluate the biological activities of $S$. minor subsp. muricata root extracts. Antioxidant, antimicrobial and antiinflammatory effects were studied in vitro. Oxidative stress parameters in sepsis were studied after the application of $S$. minor extract on the animal sepsis model.

\section{EXPERIMENTAL}

\section{Plant material}

The fresh plant was collected from fields of village Kamenica in the Sumadija region of Central Serbia, on sunny days during springtime. The plant material was identified at the Institute for Biology and Ecology at the Faculty of Science, University of Kragujevac, Serbia, by standard botanical keys for plant determination $(1,2)$. The roots were cleaned from soil and dried at room temperature, in draft and dark place. After drying, the roots of $S$. minor were ground to powder and extract with reflux of solvent (96\% ethanol, methanol and chloroform) at boiling temperature for four hours. The dry extracts were obtained by the rotary vacuum evaporator and stored in the desiccator until the experiment.

\section{Total phenolic and flavonoid content}

The total phenolic content of extracts (TPC) was determined by the Folin-Ciocalteu method. The absorbance of the reaction mixture was measured at $750 \mathrm{~nm}$ after storing in a dark place for $30 \mathrm{~min}$. All the measurements were done in triplicate. Gallic acid was used as a referent substance and the results were expressed as $\mu \mathrm{g}$ of gallic acid equivalents (GAE) per mg of dry weight ( $\mu \mathrm{g}$ GAE per mg dw) $(19,20)$.

The total flavonoid content of extracts (TFC) was determined by the aluminum chloride colorimetric method. The absorbance of the reaction mixture was measured spectrophotometrically at 510 $\mathrm{nm}$. All the measurements were done in triplicate. The reference substance was rutin and the results were expressed as $\mu \mathrm{g}$ of rutin equivalent per mg dry weight. (21).

\section{Antioxidant activity assays \\ ABTS radical scavenging activity}

Free radical scavenging activity of $S$. minor extracts was determined by 2,2 '-azino-bis-(3-ethylbenzothiazoline-6-sulfonic acid) (ABTS) radical cation decolorization assay. The absorbance of the mixture of each extract and diluted ABTS solution was measured at $734 \mathrm{~nm}$ after 6 minutes at room temperature. All the measurements were carried out three times. Trolox was used as a referent substance and the results were expressed as $\mu \mathrm{g}$ of Trolox equivalents (TE) per mg dry extract weight ( $\mu \mathrm{g}$ TE per $\mathrm{mg} \mathrm{dw}$ ) (20).

\section{DPPH free radical scavenging assay}

Total free radical scavenging capacity of the investigated samples was estimated using the stable 1,1-diphenyl-2-picrylhydrazyl (DPPH) radical, according to Dimitrijevic et al. The mixture of methanolic DPPH solution and tested extract in a total volume of $4 \mathrm{~mL}$ was prepared. After shaking and storing in the dark place for $60 \mathrm{~min}$, the absorbance was measured at $515 \mathrm{~nm}$ spectrophotometrically. All the measurements were carried out three times. A calibration curve was plotted using percent of DPPH scavenged versus concentration of Trolox as a positive control. The results were expressed as $\mu \mathrm{g}$ of Trolox equivalents (TE) per mg dry extract weight ( $\mu$ g TE per mg dw) (20). 


\section{Cupric reducing antioxidant capacity (CUPRAC) assay}

The CUPRAC assay was performed according to Dimitrijevic et al. The absorbance of the reaction mixture was measured at $450 \mathrm{~nm}$ spectrophotometrically. The results were expressed as $\mu \mathrm{g}$ of Trolox equivalents per mg of dry weight ( $\mu \mathrm{g}$ TE per mg dw) (20).

\section{Ferric-reducing antioxidant power (FRAP) assay}

Ferric reducing antioxidant power assay of investigated extracts was carried out according to Dimitrijevic et al. The absorbance of the mixture of FRAP reagent and the sample was measured at 595 $\mathrm{nm}$ after 5 minutes incubation at $37^{\circ} \mathrm{C}$. All the measurements were done in triplicate. The results were obtained using a standard calibration curve and expressed as a $\mu \mathrm{g} \mathrm{Fe} / \mathrm{mg} \mathrm{dw}$ of $\mathrm{Fe}(\mathrm{II})$ equivalents per mg of dry weight ( $\mu$ g Fe per mg dw) (20).

\section{Total reducing power (TRP) assay}

The reducing power of analyzed extracts was determined by the method which was based on the reduction of $\mathrm{Fe}$ (III) hexacyanate to $\mathrm{Fe}$ (II) hexacyanate. The absorbance of the reaction mixture was measured at $700 \mathrm{~nm}$, spectrophotometrically. All the measurements were done in triplicate. The results were expressed as $\mu \mathrm{g}$ of ascorbic acid equivalents per mg of dry extract weight ( $\mu$ g AAE per mg dw) (20).

\section{Antimicrobial activity assay}

The in vitro antimicrobial activity of the $S$. minor radix extracts was determined using a microwell dilution assay (CLSI 2009, with some modifications). The initial concentration of the extracts was $100 \mathrm{mg} / \mathrm{mL}$. Antibacterial activity of the extracts was tested against three Gram-positive bacteria (Bacillus cereus, Enterococcus faecalis, Staphylococcus aureus) and six Gram-negative bacteria (Escherichia coli, Pseudomonas aeruginosa, Enterobacter aerogenes, Proteus mirabilis, Klebsiella pneumoniae, Salmonella enteritidis). Antifungal activity of the extracts was tested against Candida albicans. Bacterial suspensions were prepared from an overnight culture in sterile saline $(0.9 \% \mathrm{NaCl})$ and their optical density was standardized to 0.5 McFarland. The serial dilutions of extracts were prepared and tested in the range of 0.04 to $100.0 \mathrm{mg} / \mathrm{mL}$ in a $96 /$ well microtiter plate with inoculated Mueller-Hinton broth. The final volume was $100 \mu \mathrm{L}$ and the final bacterial suspension was $10^{6} \mathrm{CFU} / \mathrm{mL}$ per each well. The procedure was repeated for fungal suspension with appropriate
Sabouraud Dextrose agar. Serial dilutions of DMSO $(100 \%)$ in the concentration range of 0.02 to 50.0 $\mathrm{mg} / \mathrm{mL}$ served as a negative control. Doxycycline and nystatin in the concentration range of 0.01-20.0 $\mu \mathrm{g} / \mathrm{mL}$ were used as a positive control. Bacterial and fungal growth was detected after adding $20 \mu \mathrm{L} 0.5 \%$ triphenyl tetrazolium chloride solution. The results were presented as MIC/MBC in $\mathrm{mg} / \mathrm{mL}$. Minimum inhibitory concentration (MIC - concentration of samples without visible growth) and minimal bactericidal/fungicidal concentration (MBC/MFC - concentration of samples that killed $99.9 \%$ of bacterial/fungi cells) were done in triplicate.

\section{In vitro anti-inflammatory testing Cyclooxygenase-1 inhibition assessment}

Prior to the in vivo inflammation model, an in vitro testing was done. Cyclooxygenase-1 (COX-1) inhibition assessment of $S$. minor ethanol extract was performed. The COX-1 assay was conducted in a microtiter scale with purified COX-1 from ram seminal vesicles, according to the previously used method (22). The tested concentration of the extract was $50 \mu \mathrm{g} / \mathrm{ml}$ and the result is presented as the percentage of inhibition. Indomethacin as the COX-1 inhibitor was used as a positive control. The result is a mean value of measurements that were done in triplicate.

\section{In vivo model of sepsis Animals}

The study was approved by the Ethics Committee for Animal Welfare of the Military Medical Academy and the Ministry of Agriculture and Environmental Protection of Republic of Serbia (No. 323-07-7363/2014-05) that respects the rules of the European Parliament's Directive on the protection of animals used for scientific purposes 2010/63/EU. The experiment was conducted on adult, eleven-weeks old, male Wistar rats, weighing between 250 and $300 \mathrm{~g}$. The rats were housed inside climate-controlled conditions with ad libitum access to food and water prior to the experiment. The animals were randomly divided into sepsis and control groups. Within both groups, there were six subgroups, with six animals in each subgroup.

\section{Animal model of sepsis}

Sepsis was induced by cecal ligation and puncture (CLP model). Before the procedure, the animals were anesthetized intraperitoneally with sodiumpentobarbital (45 $\mathrm{mg} / \mathrm{kg}$ body weight - b.w.). The operative procedure included several phases: the middle incision at the venter, cecum ligation one 
centimeter from the distal end, puncture of the ligated cecum, and closing of the abdominal wall. The Control group of animals were sham-operated without CLP. All animals had free access to food and water after the operation procedure (23).

\section{Experimental procedure}

The effect of ethanol extract of $S$. minor radix was evaluated on a rat model with induced sepsis. The tested extract was administered both orally and intraperitoneally (i.p.). Two different concentrations $(100 \mathrm{mg} / \mathrm{kg}$ and $300 \mathrm{mg} / \mathrm{kg}$ ) were used orally, while a single concentration $(100 \mathrm{mg} / \mathrm{kg})$ was used i.p. The plasma levels of total sulfhydryl groups (total$\mathrm{SH})$, thiobarbituric acid reactive species (TBARS), nitrate and nitrite (NOx), superoxide anion radical $\left(\mathrm{O}_{2}^{-}\right)$and superoxide dismutase (SOD) were measured. The effect of extract given intraperitoneally in a concentration of $300 \mathrm{mg} / \mathrm{kg}$ could not be evaluated, because the deaths were recorded in this animal group.

Animals were randomly assigned to the sepsis (CLP) group or to the sham-operated (control) group. Two hours before surgery, animals in the sham group received $0.5 \mathrm{~mL} \mathrm{H}_{2} \mathrm{O}$. The doses of extract for the oral application were prepared as a suspension of extract in the mixture of solvents (water/ethanol $50: 50$ ). Animals were treated by once-daily oral applications of $S$. minor root extract at a dose of $100 \mathrm{mg} / \mathrm{kg}$ (S1 group) or $300 \mathrm{mg} / \mathrm{kg}$ (S2) during one week. Animals that have been induced on sepsis (S1+CLP and S2+CLP) and sham-operated animals (S1+sham) received orally the same extract one week before the surgery. The experiment included also i.p. application of the extract at a dose of $100 \mathrm{mg} / \mathrm{kg}$, which was prepared as a suspension of extract in the mixture of solvents (water/ethanol $65: 35$ ). The experiment was performed along with 6 adequate control groups of animals - sham-operated animals, animals that were treated only by the mixture of solvents (water/ethanol $50: 50$ ), animals that were treated only by the mixture of solvents (water/ethanol $65: 35$ ), animals without treatment by the extract and without induced sepsis, animals without treatment by extract and with induced sepsis, and the animals treated by the extract, but without induced sepsis. Rats were killed $24 \mathrm{~h}$ after induced sepsis, sham operation or application of the last dose of the extract.

\section{Determination of oxidative stress parameters}

The level of total sulfhydryl groups (total $\mathrm{SH}$ ) was measured spectrophotometrically at $412 \mathrm{~nm}$, according to the method described by Sedlak and Lindsay. The principle of the method is based on the reduction of DTNB reagent by thiol groups to yellow color mercaptobenzoic acid (24). The results were expressed in $\mathrm{mM} / \mathrm{L}$.

The level of thiobarbituric acid reactive species (TBARS) was measured spectrophotometrically at $532 \mathrm{~nm}$ according to the method described by Girotti (25). The results were expressed in $\mathrm{uM} / \mathrm{L}$

Nitrate and nitrite concentration (NOx) was determined by a spectrophotometric assay based on the Griess reagent. The absorbance was measured at $492 \mathrm{~nm}$. The results were expressed as $\mathrm{nmol} / \mathrm{ml}$ (26).

Superoxide anion was detected with nitroblue tetrazolium (NBT). The method was based on the reduction of NBT by the investigated sample and the extinction change was monitored for five minutes at $515 \mathrm{~nm}$. The results were expressed as $\mathrm{nM}$ $\mathrm{NBT} / \mathrm{min} / \mathrm{mL}$ (27).

Superoxide dismutase activity was determined as a percentage of adrenaline auto-oxidation in an alkaline environment. The auto-oxidation was monitored spectrophotometrically at $480 \mathrm{~nm}$ for ten minutes. The results were expressed as $\mathrm{U} / \mathrm{ml}$ (28).

\section{Statistical analysis}

Statistical analyses were performed using SPSS version 19.0 (SPSS Inc., Chicago, Illinois, US). Descriptive data are expressed as the mean

Table 1. Antioxidant effect of S. minor extracts.

\begin{tabular}{|c|c|c|c|c|c|c|c|}
\hline $\begin{array}{c}\text { S. minor } \\
\text { extracts }\end{array}$ & $\begin{array}{c}\text { ABTS } \\
\mu \mathrm{g} \mathrm{TE} / \mathrm{mg}\end{array}$ & $\begin{array}{c}\text { DPPH } \\
\mu \mathrm{T} \text { TE/mg }\end{array}$ & $\begin{array}{c}\text { CUPRAC } \\
\mu \mathrm{g} \text { TE/mg }\end{array}$ & $\begin{array}{c}\text { FRAP } \\
\mu g \text { Fe/mg }\end{array}$ & $\begin{array}{c}\text { TRP } \\
\mu g \text { AAE/mg }\end{array}$ & $\begin{array}{c}\text { TPC } \\
\mu g \text { GAE/mg }\end{array}$ & $\begin{array}{c}\text { TFC } \\
\mu g \text { RE/mg }\end{array}$ \\
\hline Ethanol & $77.54 \mathrm{a}^{* *}$ & $96.51 \mathrm{a}^{* *}$ & $346.49 \mathrm{a}^{* *}$ & $188.22 \mathrm{a}^{* *}$ & 1.16 & $457.45 \mathrm{a}^{* *}$ & 936.50 \\
& \pm 0.16 & \pm 0.07 & \pm 0.14 & \pm 0.5 & \pm 0.01 & \pm 4.59 & \pm 17.50 \\
\hline Methanol & $76.97 \mathrm{a}^{* *}$ & $97.29 \mathrm{a}^{* *}$ & $343.35 \mathrm{a}^{* *}$ & $214.02 \mathrm{a}^{* *}$ & 1.19 & $497.47 \mathrm{a}^{* *}$ & 836.50 \\
& \pm 10.23 & \pm 0.04 & \pm 0.13 & \pm 0.32 & \pm 0.02 & \pm 3.80 & \pm 18.92 \\
\hline Chloroform & $46.11 \mathrm{~b}^{* *}$ & $40.51 \mathrm{~b}^{* *}$ & $96.80 \mathrm{~b}^{* *}$ & $48.02 \mathrm{~b}^{* *}$ & 0.11 & $41.45 \mathrm{~b}^{* *}$ & 939.00 \\
& \pm 1.03 & \pm 0.12 & \pm 0.14 & \pm 0.63 & \pm 0.02 & \pm 0.54 & \pm 13.92 \\
\hline
\end{tabular}

Different letters in superscript in the same column indicate significant difference at $\mathrm{p}<0.01(* *)$. 
Table 2. Antimicrobial activity of $S$. minor extracts (MIC/MBC in $\mathrm{mg} / \mathrm{mL}$ ) and positive controls (MIC/MBC(MFC) in $\mu \mathrm{g} / \mathrm{mL}$ ) against pathogenic microbial strains.

\begin{tabular}{|c|c|c|c|c|c|}
\hline \multirow{2}{*}{ Microorganisms } & \multirow{2}{*}{ ATCC } & \multicolumn{3}{|c|}{ S. minor extracts } & \multirow{2}{*}{$\begin{array}{c}\text { Positive controls } \\
\text { Doxycyclin/Nystatin }\end{array}$} \\
\hline & & Ethanol & Methanol & Chloroform & \\
\hline \multicolumn{5}{|c|}{ Gram-negative bacteria } & \\
\hline E. coli & 25922 & $12.50 / 50.0$ & $6.25 / 12.50$ & $0.20 / 6.25$ & $15.61 / 15.61$ \\
\hline P. aeruginosa & 9027 & $12.5 / 25.0$ & $6.25 / 25.0$ & $0.39 / 1.56$ & $15.61 / 15.61$ \\
\hline S. enteritidis & 13076 & $12.50 / 25.0$ & $6.25 / 12.50$ & $0.78 / 0.78$ & $0.90 / 1.90$ \\
\hline P. mirabilis & 12453 & $12.5 / 25.0$ & $12.5 / 25.0$ & $0.39 / 6.25$ & $7.81 / 15.61$ \\
\hline K. pneumoniae & 10031 & $12.5 / 25.0$ & $12.5 / 25.0$ & $0.39 / 6.25$ & $15.61 / 15.61$ \\
\hline E. aerogenes & 13048 & $12.5 / 25.0$ & $12.5 / 25.0$ & $1.56 / 6.25$ & $7.81 / 15.61$ \\
\hline \multicolumn{5}{|c|}{ Gram-positive bacteria } & \\
\hline B. cereus & 11778 & $12.50 / 50.0$ & $6.25 / 12.5$ & $0.10 / 0.39$ & $0.90 / 15.61$ \\
\hline S. aureus & 25923 & $25.0 / 25.0$ & $6.25 / 12.50$ & $0.10 / 0.39$ & $7.81 / 15.61$ \\
\hline E. faecalis & 19433 & $6.25 / 12.50$ & $6.25 / 6.25$ & $0.39 / 0.39$ & $0.90 / 1.90$ \\
\hline \multicolumn{5}{|c|}{ Fungi } & \\
\hline C. albicans & 14053 & $12.50 / 25.0$ & $12.50 / 50.0$ & $12.50 / 25.0$ & $7.81 / 15.61$ \\
\hline
\end{tabular}

value \pm standard deviation (SD). Student's t-test, one-way analysis of variance (ANOVA) and appropriate nonparametric test (Mann-Whitney) were used to identify significant differences in the data. Differences were considered statistically significant if $\mathrm{p}<0.05$ and highly significant if $\mathrm{p}<0.01$.

\section{RESULTS}

\section{Antioxidant activity assays}

Antioxidant capacity of S. minor extracts, evaluated by five different methods, as well as total phenolic (TPC) and flavonoid content (TFC) are presented in Table 1. These results represent the mean value \pm standard deviation of three replicate experiments (Table 1).

Methanol and ethanol extracts presented high phenol content; in contrast, the chloroform extract showed more than ten times lower phenol content. Methanol extract contained the highest level of phenols in comparison to the other two investigated extracts. The lowest level of TPC was present in chloroform extract. There was a highly significant difference between TPC from methanol and chloroform extract and between ethanol and chloroform extract. However, there was no significant difference between the flavonoid content of all the investigated extracts.

Antioxidant activity of three different $S$. minor extract was evaluated using two free radical scavenging assays, DPPH and ABTS. The DPPH and ABTS radical scavenging potential of the methanol and ethanol extract was found to be significantly higher than chloroform extract $(\mathrm{p}<0.01)$. The activity of methanol and ethanol extract was lower in the ABTS over the DPPH assay.

The highest CUPRAC capacity was observed for ethanol extract followed by methanol extract and the lowest activity was shown by chloroform extract. Methanol and ethanol extract of $S$. minor showed significantly higher antioxidant activity than chloroform extract, measured by the CUPRAC assay $(\mathrm{p}<0.01)$. Considering the results of the ferric reducing antioxidant power assay, the highest antioxidant activity was observed for methanol and ethanol extract. The FRAP value for chloroform extract was nearly five times lower than the FRAP value for methanol extract $(\mathrm{p}<0.01)$.

The results of total reducing power for ethanol and methanol extracts are similar. Among the tested samples, methanol extract showed the highest total reducing power, followed by ethanol extract, while chloroform extract showed ten times weaker reducing power than methanol and ethanol extract.

\section{Antimicrobial activity assay}

The results of in vitro antimicrobial activity of S. minor subsp. muricata extracts against nine bacterial and one fungus strain are presented in Table 2. The MIC and MBC values of extracts varied from 0.10 to $25.0 \mathrm{mg} / \mathrm{mL}$ and 0.39 to $50.0 \mathrm{mg} / \mathrm{mL}$, respectively.

The chloroform extract of $S$. minor radix showed the strongest antibacterial activity among 
investigated extracts, both on Gram-positive and Gram-negative bacteria (Table 2). Chloroform extract exhibited bacteriostatic activity with MIC = 0.1-1.56 $\mathrm{mg} / \mathrm{mL}$, while bactericidal effect was ranged $0.39-6.25 \mathrm{mg} / \mathrm{mL}$. B. cereus and $S$. aureus showed the highest sensitivity to the chloroform extract with MIC and MBC values $0.10 \mathrm{mg} / \mathrm{mL}$ and $0.39 \mathrm{mg} / \mathrm{mL}$, respectively.

MIC and MBC values of methanol extracts varied from 6.25 to $12.5 \mathrm{mg} / \mathrm{mL}$ and 6.25 to 25.0

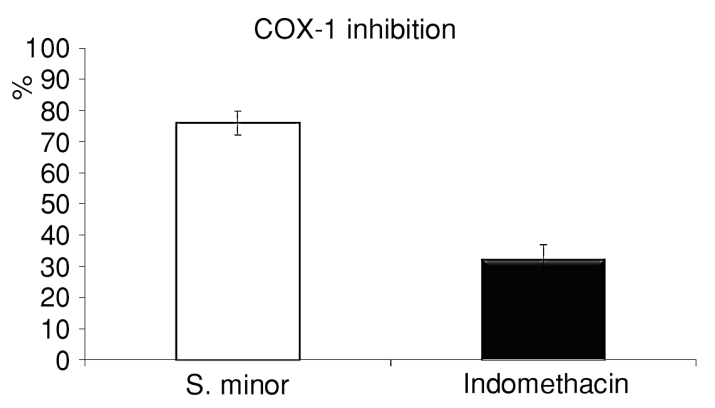

Figure 1. The percentage of inhibition of COX-1 isoenzyme caused by $S$. minor radix ethanol extract. i.p. - intraperitoneally $\mathrm{mg} / \mathrm{mL}$, respectively. $\mathrm{MIC}$ and $\mathrm{MBC}$ values of ethanol extracts varied from 6.25 to $50.0 \mathrm{mg} / \mathrm{mL}$ and 12.50 to $50.0 \mathrm{mg} / \mathrm{mL}$, respectively. $S$. enteritidis, $E$. coli, P. aeruginosa, B. cereus, $S$. aureus and E. faecalis were more susceptible to methanol extract than ethanol extract of $S$. minor.

All the extracts revealed moderate antifungal activity against $C$. albicans, with extracts showing the MIC $12.50 \mathrm{mg} / \mathrm{mL}$ and MFC values, ranging between 25,0 and $50.0 \mathrm{mg} / \mathrm{mL}$. Nystatin was applied as a positive control and presented MIC $7.81 \mu \mathrm{g} / \mathrm{mL}$ and MFC $15.61 \mu \mathrm{g} / \mathrm{mL}$.

\section{Inhibition of COX-1 isoenzyme by $\mathrm{S}$. minor radix extract}

Ethanol extract of $S$. minor radix was tested for inhibition of COX-1 isoenzyme. The inhibition of COX-1 isoenzyme by $S$. minor radix extract was evaluated in the concentration of $50 \mu \mathrm{g} / \mathrm{mL}$. The tested extract showed $76 \pm 3.76 \%$ of inhibition of COX-1 isoenzyme in the presence of reversible COX inhibitor, Indomethacin, as a positive control (Fig. 1). Indomethacin exhibited $32 \pm 4.76 \%$ of COX-1 inhibition, which is more than two times weaker than the effect of the $S$. minor ethanol extract.
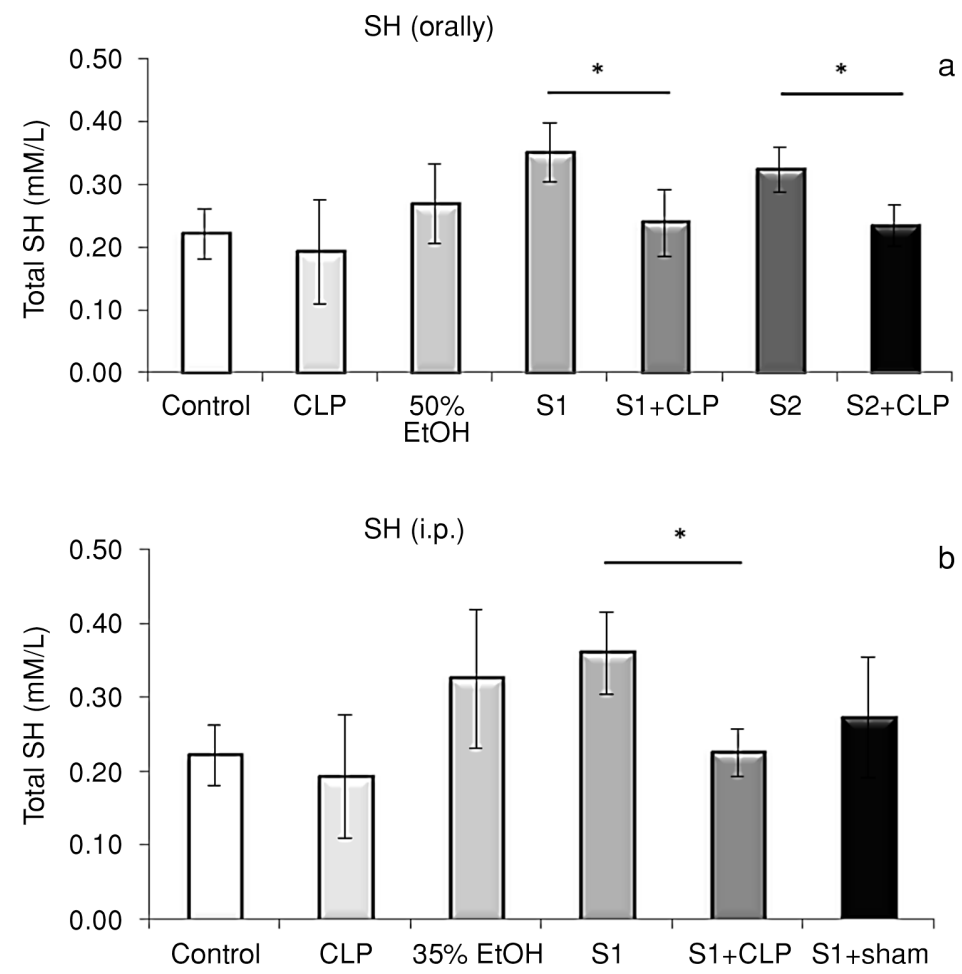

Figure 2. Total-SH levels in the groups treated with $S$. minor radix ethanol extract. Data are presented as following: a - orally administration of extract; $\mathrm{b}$ - intraperitoneal administration of the extract. The results are expressed as mean $\pm \mathrm{SD}(* \mathrm{p}<0.05 ; * * \mathrm{p}<0.01)$. i.p. - intraperitoneally 

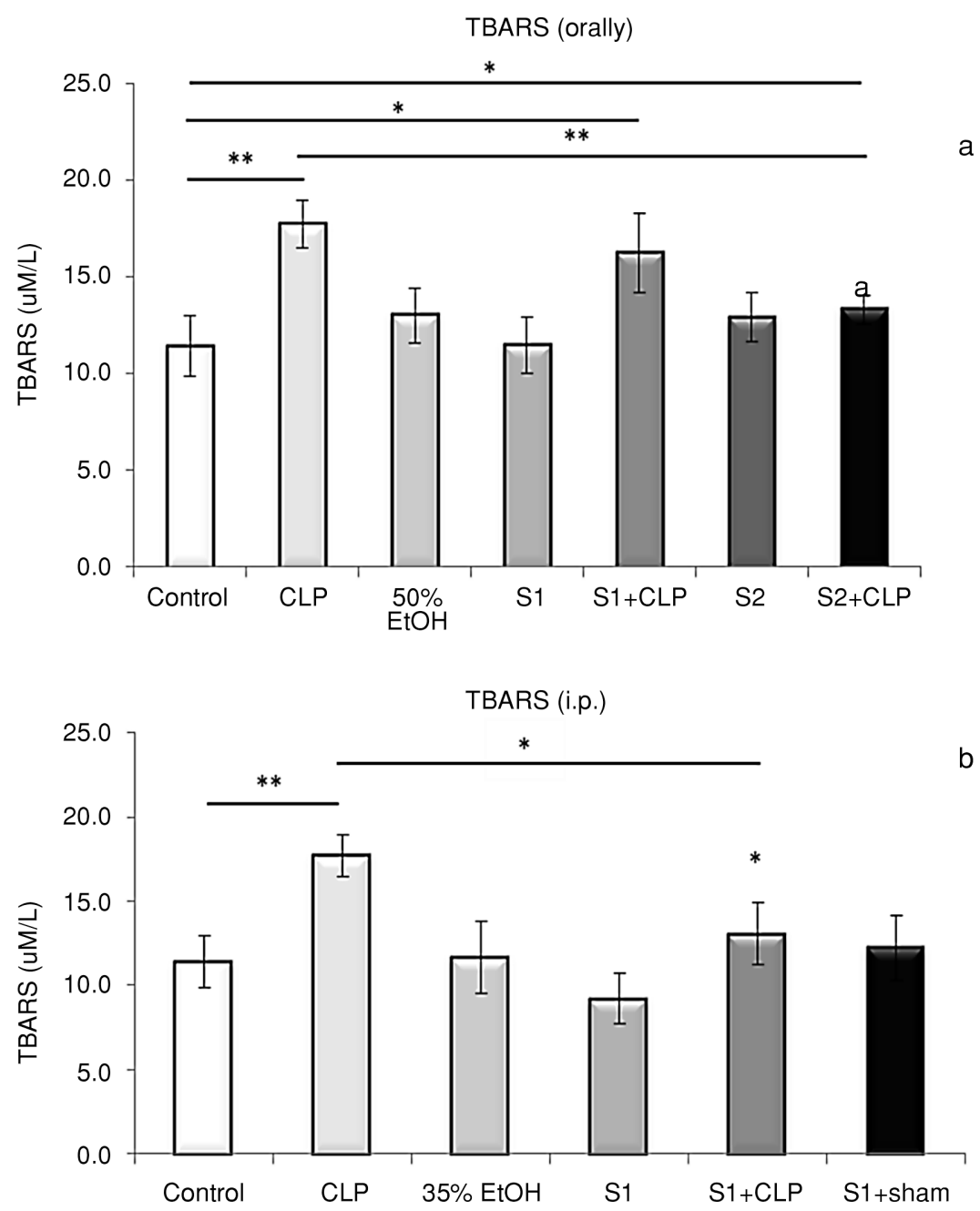

Figure 3. TBARS levels in the groups treated with $S$. minor radix ethanol extract. Data are presented as following: a - orally administration of extract; $b$ - intraperitoneal administration of the extract. The results are expressed as mean $\pm \operatorname{SD}(* \mathrm{p}<0.05 ; * * \mathrm{p}<0.01)$. i.p. - intraperitoneally

Effects of S. minor radix extract on sepsis animal model

The effect of ethanol extract of $S$. minor radix on oxidative stress parameters in the animal model of sepsis was evaluated. The tested extract was administered orally in 2 different concentrations $(100 \mathrm{mg} / \mathrm{kg}$ and $300 \mathrm{mg} / \mathrm{kg}$ ) and i.p. in one concentration $(100 \mathrm{mg} / \mathrm{kg})$. There were no significant differences in values of total-SH between the control group of animals without any treatment and groups of animals treated orally and i.p. by $S$. minor radix extract in all tested concentrations.

The values of total SH-levels in groups treated orally by extract are presented in Figure 2a. The orally applied extract did not affect significantly the total-SH concentration in sepsis. However, there was a decrease of total-SH in the CLP group treated by $100 \mathrm{mg} / \mathrm{kg} S$. minor radix extract, in relation to the $\mathrm{S} 1$ group $(\mathrm{p}=0.007)$. The same pattern was observed between analog treated and control groups $-300 \mathrm{mg} / \mathrm{kg}$ applied orally $(\mathrm{p}=0.034)$. The difference in the concentrations of extracts used in the experiment could not significantly influence the total-SH level ( $p>0.05)$. Intraperitoneal administration of $S$. minor radix extract had no significant influence on the value of total-SH in the CLP group. The total-SH level in groups treated by i.p. administration of the extract is presented in Figure $2 b$. The same pattern, like in the case of orally administered extracts was observed - there was a significant decrease of total-SH in the CLP group treated i.p. by the extract, in relation to the $S 1$ group ( $p=0.027$ ).

The mean values of TBARS measured in the groups of animals treated orally by $S$. minor radix 
extract are presented in Figure 3a. There was a significant decrease in the TBARS level in the sepsis group treated by the extract $(\mathrm{S} 2+\mathrm{CLP})$ related to the CLP group $(\mathrm{p}<0.01)$. This correlation however was not observed between the group treated by lower extract concentration (S1+CLP) and the CLP group. Level of TBARS in sham-operated (control) group is different from level of TBARS in CLP groups treated orally by both concentrations $-100 \mathrm{mg} / \mathrm{kg}$ and $300 \mathrm{mg} / \mathrm{kg}(\mathrm{p}=0.008, \mathrm{p}=0.04$ respectively). The mean TBARS values in the experiment after i.p. administration of $S$. minor radix extract are presented in Figure 3b. TBARS level in the CLP group after i.p treatment by the tested extract was significantly lower compared to the control CLP group ( $\mathrm{p}=$ 0.004).

The mean values of total nitrate and nitrite plasma level in the groups treated orally by the
S. minor extract are presented in Figure 4a, while the results obtained after i.p. administration are shown in Figure 4b. As it is expected, the $\mathrm{NO}_{\mathrm{x}}$ value in the control sepsis group (CLP) was increased related to the control, sham-operated, group $(\mathrm{p}<0.01)$. The level of $\mathrm{NO}_{\mathrm{x}}$ in the CLP group treated orally by the extract in the concentration $100 \mathrm{mg} / \mathrm{kg}(\mathrm{S} 1+\mathrm{CLP})$ was significantly lower compared to the control and CLP group ( $\mathrm{p}<0.05, \mathrm{p}<0.01$ respectively). The higher concentration of the extract in S2+CLP group caused a significant decrease in $\mathrm{NO}_{\mathrm{x}}$ related to the CLP group $(\mathrm{p}<0.01)$. Intraperitoneal administration of $S$. minor extract did not affect the $\mathrm{NO}_{\mathrm{x}}$ level in S1+CLP group related to CLP or control groups.

The obtained mean values of superoxide anion radical plasma levels are presented in Figure $5(5 \mathrm{a}$ after orally applied and $5 \mathrm{~b}$ after i.p. applied extract). The level of $\mathrm{O}_{2}^{-}$was significantly higher in the CLP
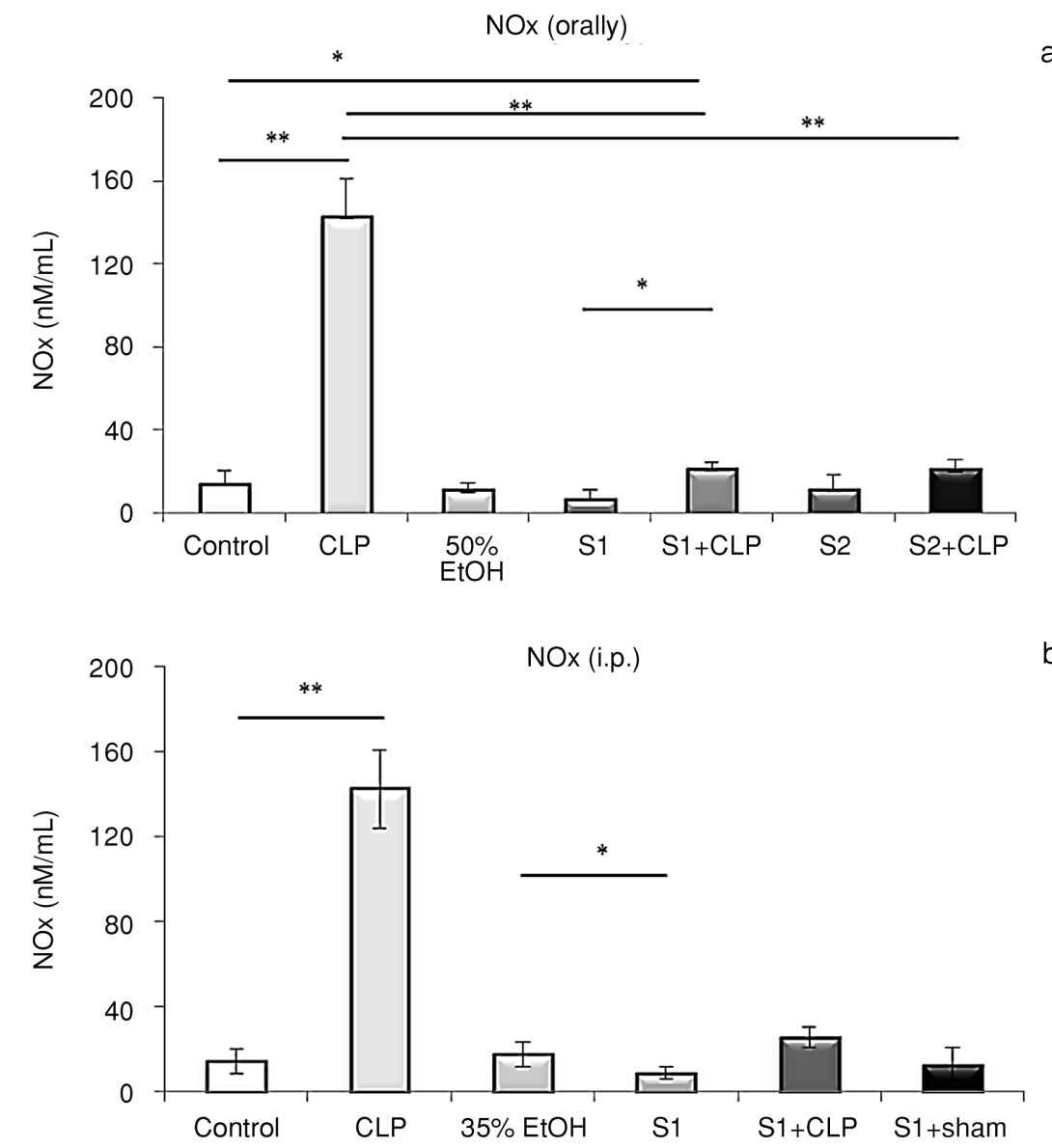

Figure 4. Nitrate and nitrite concentration $\left(\mathrm{NO}_{\mathrm{x}}\right)$ in the groups treated with $S$. minor radix ethanol extract. Data are presented as following: $\mathrm{a}-$ orally administration of extract; $\mathrm{b}-$ intraperitoneal administration of the extract. The results are expressed as mean $\pm \mathrm{SD}(* \mathrm{p}<0.05$; $* * \mathrm{p}<0.01)$.

i.p. - intraperitoneally 

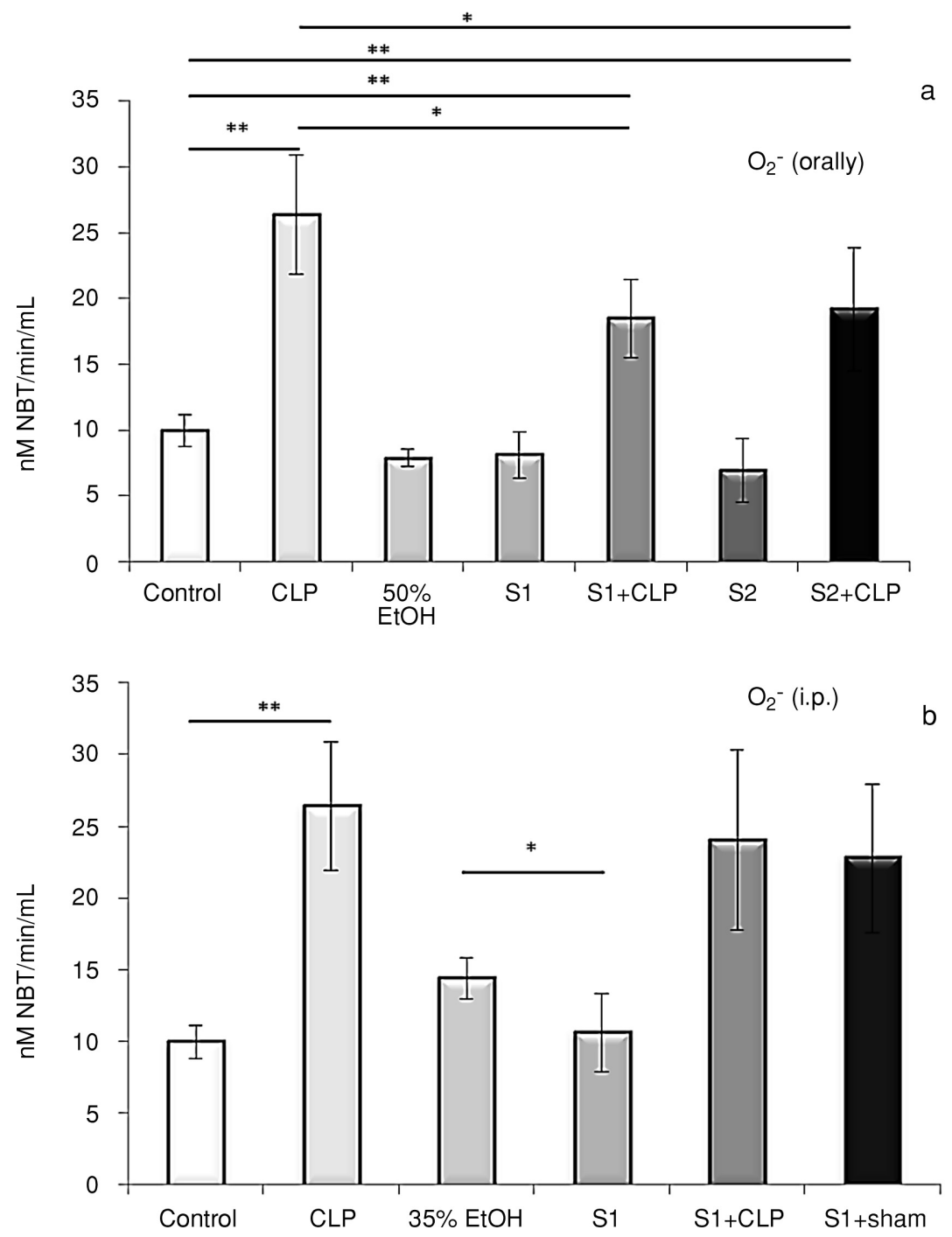

Figure 5. Superoxide anion radical $\left(\mathrm{O}_{2}{ }^{-}\right)$level in the groups treated with $S$. minor radix ethanol extract. Data are presented as following: a - orally administration of extract; $\mathrm{b}-$ intraperitoneal administration of the extract. The results are expressed as mean $\pm \mathrm{SD}(* \mathrm{p}<0.05 ; * * \mathrm{p}$ $<0.01)$.

i.p. - intraperitoneally

group compared to the control group regardless of the way of administration $(\mathrm{p}<0.01)$. Orally applied $S$. minor radix extract in sepsis $(\mathrm{S} 1+\mathrm{CLP}$ and $\mathrm{S} 2+\mathrm{CLP}$ groups) caused a significant decrease in $\mathrm{O}_{2}{ }^{-}$ level related to the CLP group. However, the level of $\mathrm{O}_{2}{ }^{-}$was significantly lower in the control group compared to S1+CLP and S2+CLP groups. Intraperitoneally applied extract in the sepsis group did not affect the superoxide anion level in comparison to the control and CLP groups.

Superoxide dismutase (SOD) activity in the sepsis groups treated orally with $S$. minor radix ethanol extract in both concentrations was signifi- cantly higher compared to the CLP group (Fig. 6a). There was a significant difference in SOD activity between the control group and S1+CLP group after i.p. administration of the extract (Fig. 6b).

A significant decrease of TBARS level was obtained in the CLP group after i.p. treatment by $S$. minor extract $(100 \mathrm{mg} / \mathrm{kg})$ in comparison to the orally applied extract of the same concentration ( $p$ $<0.05$ ). There were no significant differences in the value of total-SH, NOx, $\mathrm{O}_{2}$ and $\mathrm{SOD}$ levels between CLP groups after oral and i.p. treatment by the extract in the same concentration $(p>0.05)$ (Fig. 7). 


\section{DISCUSSION AND CONCLUSION}

In order to complete existing data on the biological activities of $S$. minor, we have studied different root extracts of $S$. minor subsp. muricata for its antioxidant, antimicrobial and anti-inflammatory (in vitro and in vivo) effects.

The antioxidant potential of three $S$. minor radix extracts was compared (methanol, ethanol and chloroform). The content of main antioxidant-contributing compounds was determined (phenols and flavonoids). Methanol extract contained the highest level of phenols in comparison to the other two investigated extracts $(497.47 \pm 3.80 \mu \mathrm{g}$ GAE $/ \mathrm{mg}$ $\mathrm{dw})$. The lowest level of TPC was present in chloroform, as a nonpolar solvent (41.45 $\pm 0.54 \mu \mathrm{g}$ $\mathrm{GAE} / \mathrm{mg} \mathrm{dw}$ ). Considering that the data about
S. minor subsp. muricata are scarce, we may look upon these results in the light of the data available on $S$. minor L. Romojaro et al. reported the total phenolic content in $S$. minor of $530.51 \pm 21.12 \mathrm{mg}$ GAE/100 mg, but it was expressed on fresh plant weight (11). Also, the other source claims that $S$. minor water/ethanol extract contains high levels of polyphenols (29). The most investigated species of Sanguisorba genus seems to be $S$. officinalis. Cai et al. reported the TPC of methanol extract of S. officinalis roots to be $15.87 \mathrm{~g} \mathrm{GAE} / 100 \mathrm{~g} \mathrm{dw}$, which is considerably lower than results for phenols in our methanol extract of $S$. minor roots (49.74 g $\mathrm{GAE} / 100 \mathrm{~g} \mathrm{dw}$ ) (30). The same pattern was observed also in the case of phenols in ethanol extracts - TPC value for $S$. officinalis extract was $121.42 \pm 0.7 \mathrm{mg}$ $\mathrm{GAE} / \mathrm{g}$, while our result for $S$. minor is almost four
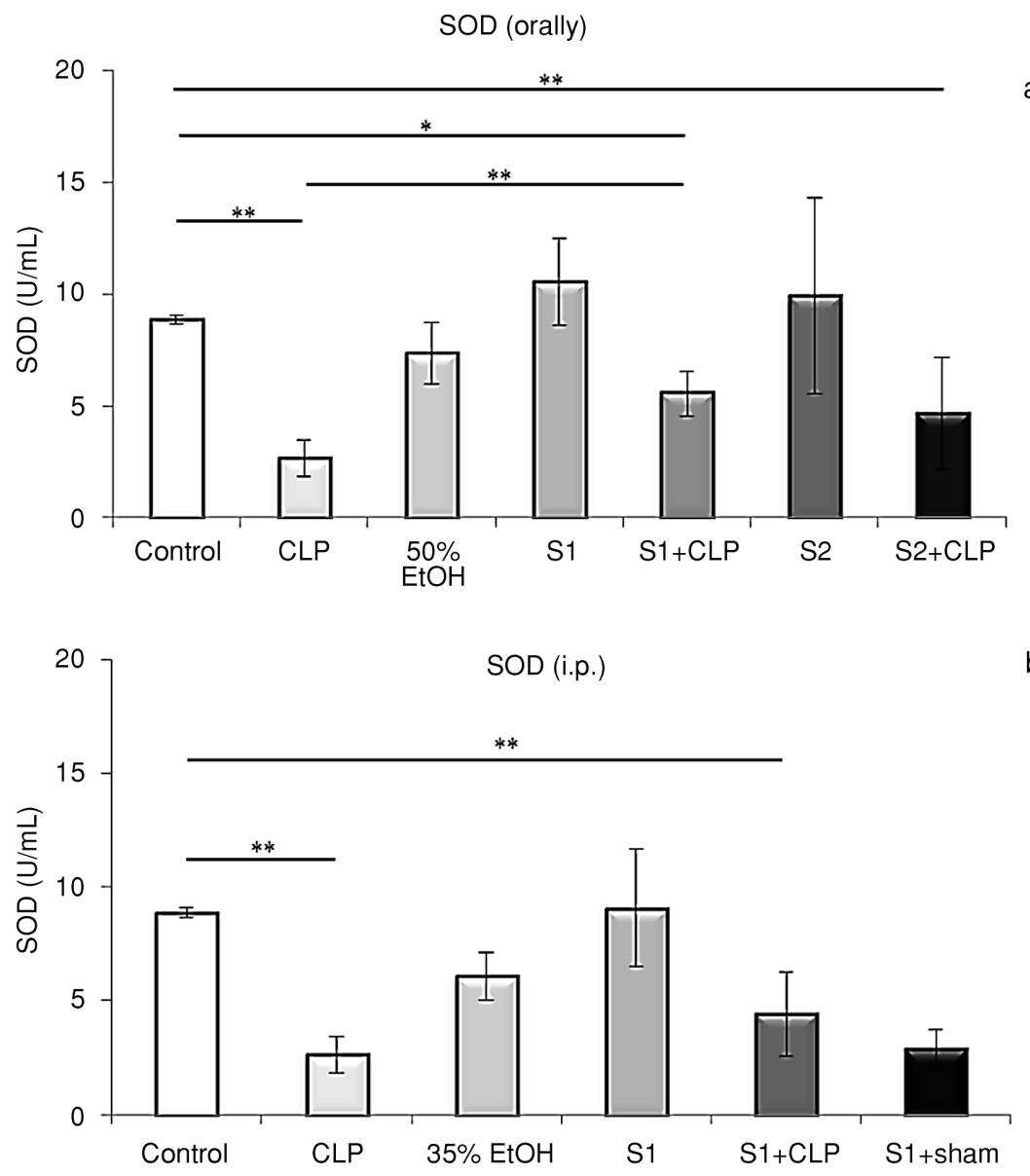

Figure 6. Superoxide dismutase (SOD) activity in the groups treated with $S$. minor radix ethanol extract. Data are presented as following: $\mathrm{a}$ - orally administration of extract; $\mathrm{b}-$ intraperitoneal administration of the extract. The results are expressed as mean $\pm \mathrm{SD}(* \mathrm{p}<0.05$; $* * \mathrm{p}<0.01)$.

i.p. - intraperitoneally 


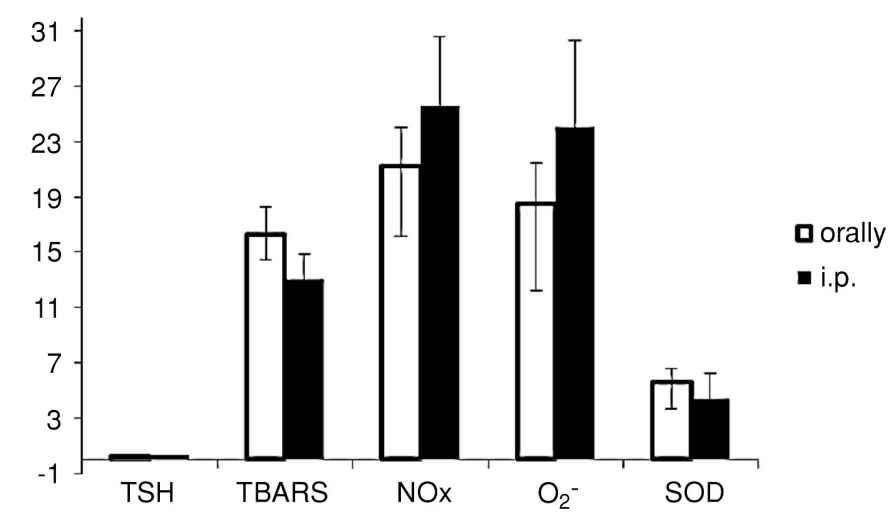

Figure 7. Comparison of oxidative stress parameters and SOD activity in the groups treated orally and intraperitoneally by $S$. minor radix ethanol extract (mean $\pm \mathrm{SD})$.

times higher $(457.45 \pm 4.59 \mathrm{mg}$ GAE/g) (10). However, this simple and direct comparison of flavonoid content from our research and previous data is not feasible, due to different equivalents for result expression (unless rutin/quercetin relation is matched using their molecular weights). The striking difference between previously published results and ours seems to be the correlation of antioxidant activity and TFC. The positive correlation between antioxidant activity and total flavonoid content was noted in aerial parts extracts of $S$. minor (31). We observed an inverse correlation between the antioxidant activity and TFC in root extracts. The chloroform extract showed the highest TFC, but the lowest antioxidant activity. Therefore, flavonoids in investigated $S$. minor extracts do not contribute significantly to the antioxidant activity. It seems that total phenols are mainly responsible for the antioxidant activity since a positive correlation was observed between antioxidant activity of ethanolic and methanolic S. minor extracts and the content of phenols in our research.

The antioxidant potential of $S$. minor extracts was evaluated by several currently approved methods (ABTS, DPPH, CUPRAC, FRAP, and TRP assays). The extract prepared in chloroform, as a less polar solvent, acted against DPPH and ABTS radical with comparable power but methanol and ethanol extracts exhibited higher scavenging potential, which may be attributed to the high level of antioxidant components in these extracts (32). The antioxidant activity of our sample measured by the ABTS assay was lower than the antioxidant activity of $S$. officinalis, according to $\mathrm{Li}$ et al. (33). The ethanol extract of $S$. minor showed slightly higher antioxidant activity than methanol extract, deter- mined by CUPRAC and FRAP method (Table 1). The lowest CUPRAC and FRAP activity was shown by chloroform extract, just as expected according to the total phenolic content. The results from this study of total reducing power for ethanol and methanol extracts are similar (Table 1). These two extracts have the highest amount of phenolics and therefore show a high reducing power (32).

Methanol and ethanol extracts did not differ significantly in the content of phenols, as well as in achieved antioxidant activity measured by five different methods, which may be due to no high differentiation in the polarity of these solvents. On the contrary, both of these extracts were superior to chloroform extract in regards to the aforementioned parameters. We assume that chloroform, due to the low polarity, could not efficiently extract all compounds that contribute to antioxidant activity (34). We have presented the comparison of antioxidant activity among our investigated extracts since we have not encountered any similar research data that could serve as a good match for comparison of antioxidant activity to investigated species $S$. minor subsp. muricata.

Antimicrobial activity of investigated S. minor subsp. muricata extracts varied depending on the group of microorganism, and the type of extracts. The chloroform extract of $S$. minor radix showed the strongest antimicrobial activity (Table 2). It exhibited strong activity against all examined strains of bacteria: B. cereus, E. faecalis, S. aureus, E. coli, $P$. aeruginosa, E. aerogenes, $P$. mirabilis, $K$. pneumoniae, S. enteritidis. B. cereus and $S$. aureus showed the highest sensitivity to the chloroform extract.

A recently published study by Finimundy et al. also reported the antibacterial efficacy of the 
$S$. minor root extracts against $S$. aureus, B. cereus, $P$. aeruginosa and $E$. coli using the microdilution method (35). Antibacterial activity of $S$. minor root extracts against $S$. aureus, B. cereus, E. coli had also been confirmed in the study of Karkanis et al. (36). The MIC and MBC values of investigated extracts in both of the studies were slightly lower than in our study for the same bacteria. These differences may be attributed to different growing conditions that can affect the bioactive potential of plant extract (35). $S$. minor root extracts also exhibited activity against Enterobacter cloacae, Listeria monocytogenes, Salmonella typhimurium, and Micrococcus flavus $(35,36)$.

In our study, all the extracts revealed similar and moderate antifungal activity against $C$. albicans. The antifungal properties of $S$. minor have been previously reported by Finimundy et al. against six fungi, namely Aspergillus fumigatus, A. Niger, A. ochraceus, Penicillium funiculosum, P. ochrochloron, and $P$. verrucosum var. cyclopium (35). Karkanis et al. recorded similar effects of the $S$. minor root extracts against the same fungi strains (36).

The literature also points out that $S$. officinalis is active against $S$. aureus, $P$. aeruginosa, C. albicans and Candida guilliermondii (37, 38). The investigated ethanol extract of $S$. minor radix showed stronger bacteriostatic activity against S. aureus, P. aeruginosa, E. coli, B. subtilis and $C$. albicans in comparison to the previously published data for ethanol extract of $S$. officinalis underground parts (MIC $=15.63-250 \mathrm{mg} / \mathrm{mL}$ ) (39). The results of the bacteriostatic activity of investigated chloroform extract of $S$. minor radix against S. aureus, P. aeruginosa, E. coli and C. albicans were similar to the chloroform extract of $S$. officinalis herbs (MIC $=0.128-1.024 \mathrm{mg} / \mathrm{mL})(38)$.

The design of conducted in vitro research included the experience of traditional medicine in Serbia, which utilizes $S$. minor in the form of ethanol extract (tincture). Since our results of the antioxidant activity showed similar activity of ethanol and methanol extract, we preferred to include ethanol extract of $S$. minor radix, in preliminary in vitro, and the following testing. In the preliminary anti-inflammatory in vitro assay, we obtained $76 \%$ of COX-1 inhibition by ethanol extract of $S$. minor, which led us to the thinking of its anti-inflammatory properties (40).

Proceeding to an animal model of sepsis, we followed oxidative stress parameters, since they are nonspecific but crucial indicators of inflammation and energy disturbances during sepsis (41, 42). Sepsis is still a leading problem, causing significant morbidity and mortality even in the era of modern technologies used in health care management. Nowadays, the focus of investigations for efficient therapy in sepsis has been slightly shifted toward the antioxidant therapies that could successfully accompany conventional therapy. Herbal extracts with antioxidative and anti-inflammatory attributes may offer arguments for playing such a role in the treatment of sepsis $(14,43)$. The effect of ethanol S. minor extract on the systemic tissue oxidative status after oral and intraperitoneal administration in rats with sepsis could be promising.

These results present the first report of the antioxidative activity of $S$. minor extract in sepsis. No change of values of total-SH, TBARS, NOx, $\mathrm{O}_{2}^{-}$ and SOD between control group without any treatment and control groups treated orally/intraperitoneally by $S$. minor extract indicates that administration of $S$. minor extract does not affect the physiological environment in which the cells signaling pathways are performed $(44,45)$. The tissue thiols availability is crucial for a metabolic challenge in systemic inflammation such as sepsis since they represent significant contributors to the body defense system against reactive oxygen species (45). Besides the antioxidant role, thiols contribute to other processes such as signal transduction, detoxification and apoptosis (46). A decreased level of thiols has been associated with various disorders, including sepsis (46). However, the administration of ethanol extract of $S$. minor to animals with sepsis did not affect the level of total thiols, neither orally nor intraperitoneally applied (Figs. 2 and 3) (47). Though basically lipid peroxidation is a measure of membrane damage, it also affects protein synthesis in all tissues, especially during aging. Furthermore, cellular dysfunctions induced by oxidative stress are mediated by lipid peroxidation end products (44, 48). Malondialdehyde generated during lipid peroxidation is considered the most important mediator of toxic effects caused by oxidative stress occurring in the cell. Excess accumulation of malondialdehyde is associated with complications in sepsis $(44,48)$. Our results indicate that $S$. minor extracts applied both orally and intraperitoneally produce a positive effect on TBARS level. Orally applied extract in the concentration of $300 \mathrm{mg} / \mathrm{kg}$ significantly decreases TBARS level compared to the CLP group (Fig. 4). Investigated extract expressed a significant decrease in values of TBARS in both tested concentrations when compared to the control group, which suggests its antioxidant effect. These results showed also that the intraperitoneal administration of $S$. minor extract was superior to oral administration, concerning the 
reduced TBARS level in sepsis. Such a positive effect of investigated extract seems to be due to high phenol content $(19,21,30)$. In particular, the effect of increased total SH content in healthy animals could be the reflection of a significant antioxidant potential of the tested extract. Literature data point to a decrease of TBARS level when vitamin $\mathrm{C}$, as a strong antioxidant, has been applied intraperitoneally. Since the investigated extract of $S$. minor also induced a decrease of TBARS level, we conclude that $S$. minor extract may have a promising role in sepsis (42). The plasma levels of nitrite and nitrate, as the final products of nitric oxide oxidation pathways, are increased in sepsis (49). Superoxide anion induces lipid peroxidation and damages the cell membranes and its level in sepsis is increased, too. This anion is involved in several reactions in which products are a variety of reactive oxygen and nitrogen species. Superoxide dismutase controls the $\mathrm{O}_{2}$ level by converting it into less active oxygen and hydrogen peroxide (50). Orally applied S. minor extract in both concentrations significantly decreased the NOx and $\mathrm{O}_{2}-$ plasma levels compared to the CLP group (Figs. 4a and 5a). The level of SOD was significantly decreased after oral administration of extract in both concentrations compared to the control group. S. minor extract in lower concentration gave increased SOD activity compared to CLP group. Intraperitoneal administration of $S$. minor extract did not show a positive effect on reduction of NOx and $\mathrm{O}_{2}^{-}$levels, while SOD activity was decreased compared to control group (Figs. 4b, 5b and $6 \mathrm{~b}$ ). It can be assumed that the route of administration of $S$. minor extract did not affect the achieved results in oxidative stress parameters reduction.

Considering the exhibited antioxidant activity and high phenolic content, $S$. minor subsp. muricata could be used as a natural antioxidant and as a nutritional supplement with high antioxidant potential. The chloroform extract of $S$. minor showed strong antibacterial activity and therefore has the potential for further more comprehensive studies. The synergistic effect of this plant extract with commonly used antibiotics could be also interesting for further investigation. Based on the achieved effects on oxidative stress parameters in an animal model of sepsis, S. minor subsp. muricata could be considered as a herbal adjuvant antioxidant therapy in systemic infectious treatment. S. minor ethanol extract induced inhibition of COX-1 in vitro which justifies the use of S. minor in traditional medicine as an anti-inflammatory agent.

The results presented in this study indicate a wide spectrum of biological properties of $S$. minor which could be used as a potential source of natural bioactive compounds in pharmaceutical and medicinal treatments. Hence, further investigations oriented on isolation and characterization of the present antioxidants, antimicrobial and anti-inflammatory substances are necessary in order to determine the effects of this plant species and the underlying mechanism.

\section{Funding}

This research did not receive any specific grant from funding agencies in the public, commercial, or not-for-profit sectors.

\section{Ethics approval and consent to participate}

The study was approved by the Ethics Committee for Animal Welfare of the Military Medical Academy and the Ministry of Agriculture and Environmental Protection of Republic of Serbia (No. 323-07-7363/2014-05) that respects the rules of the European Parliament's Directive on the protection of animals used for scientific purposes 2010/63 / EU.

\section{Acknowledgments}

This work was supported by the projects: No. MFVMA 04/19-21 of the University of Defence, Serbia and No. OI 172051, No. OI 172047, No. OI 175014 of the Ministry of Education, Science and Technological Development of Serbia.

\section{Declaration of interest statement}

The authors report no declarations of interest.

\section{REFERENCES}

1. Josifovic M.: Rosaceae family, in Flora of Serbia, Vol. 4. pp. 66-71, SANU, Belgrade 1972.

2. Tutin T.G., Heywood V.H., Burges N.A., Moore D.M., Valentine D.H., et al.: Rosaceae to Umbelliferae, in Flora Europaea, Vol. 2. pp. 33-34, Cambridge University press, Cambridge 1968.

3. Guarrera P.M., Savo V.: J. Ethnopharmacol. 185, 202 (2016).

4. Ayoub N.A.: Phytochemistry 63, 433 (2003).

5. El-Mousallamy A.M.: Pharmazie 57, 702 (2002).

6. Reher G., Reznicek G., Baumann A.: Planta Med. 57, 506 (1991).

7. Arıhan O., Özbek H., Özkan A.M.: Eastern J. Med. 20, 81 (2015). 
8. Beg S., Swain S., Hasan H., Hussain M.S.: Pharmacogn. Rev. 5, 120 (2011).

9. Gürbüz I., Ozkan A.M., Yesilada E., Kutsal O.: J. Ethnopharmacol. 101, 313 (2005).

10. Zhao Z., He X, Zhang Q., Wei X., Huang L., et al.: Am. J. Chin. Med. 45, 199 (2017).

11. Romojaro A., Botella M.Á., Obón C., Pretel M.T.: Int. J. Food Sci. Nutr. 64, 944 (2013).

12. Remick D.G.: Am. J. Pathol. 170, 1435 (2007).

13. Huang T.S., Shyu Y.C., Chen H.Y., Lin L.M., Lo C.Y., et al.: PLoS One 8, 1 (2013).

14. Matsumoto S., Koga H., Kusaka J., Hagiwara S., Shihara K. et al.: J. Anesth. Clin. Res. 2, 1 (2011).

15. Angus D.C., Linde-Zwirble W.T., Lidicker J., Clermont G., Carcillo J., et al.: Crit. Care Med. 29, 1303 (2001).

16. Laudanski K., Lapko N., Zawadka M., Zhou B.X., Danet-Desnoyers G., et al.: PloS One 12, 7 (2017).

17. Ninković M., Maličević Z., Jelenković A., Đukić M., Jovanović M., et al. Gen. Physiol. Biophys. 28, 243 (2009).

18. Yin H., Qiu M., He D., Zhang R., Tao P. et al.: Zhonghua Wei Zhong Bing Ji Jiu Yi Xue 29, 162 (2017).

19. Rajurkar N.S., Hande S.M.: Indian J. Pharm. Sci. 73, 146 (2011).

20. Dimitrijevic M., Jovanovic V.S., Cvetkovic J., Mihajilov-Krstev T., Stojanovic G., et al.: Anal. Methods. 7, 4181 (2015).

21. Baba S.A., Malik S.A.: J. Taibah Univ. Sci. 9, 449 (2015).

22. Fiebich B.L., Grozdeva M., Hess S., Hüll M., Danesch U. et al.: Planta Med. 71, 12 (2005).

23. Stojanović D., Ašanin R., Maličević Ž., Vidić B.M.: Acta Vet. 54, 281 (2004).

24. Sedlak J., Lindsay R.H.: Anal. Biochem. 25, 1192 (1968).

25. Girotti M.J., Khan N., McLellan B.A.: J. Trauma 31, 32 (1991).

26. Viinikka L.: Scand J. Clin. Lab. Invest. 56, 577 (1996).

27. Auclair C., Voisin E.: Nitroblue tetrazolium reduction, in Handbook of methods for oxygen radical research. Greenwald RA (Ed.)., pp. 123132, CRC Press Inc, Boca Raton 1985.

28. Sun M., Zigman S.: Anal. Biochem. 90, 81 (1978).

29. Vanzani P., Rossetto M., De Marco V., Sacchetti L.E., Paoletti M.G., et al.: J. Food Sci. 76, C46 (2011).

\footnotetext{
C 2020 by Polish Pharmaceutical Society. This is an access article under the CC BY NC license (http://creativecommons.org/licenses/by-nc/4.0/).
}

30. Cai Y., Luo Q., Sun M., Corke H.: Life Sci. 74, 2157 (2004).

31. Gawron-Gzella A., Witkowska-Banaszczak E., Bylka W., Dudek-Makuch M., Odwrot A., et al.: Pharm. Chem. J. 50, 244 (2016).

32. Biswas M., Haldar P.K., Ghosh A.K.: J. Nat. Sci. Biol. Med. 1, 29 (2010).

33. Li S., Li S.K., Gan R.Y., Song F.L., Kuang L. et al.: Ind. Crops Prod. 51, 289 (2013).

34. Rajauria G., Abu-Ghannam N.: Int. J. Anal. Chem. 2013, 802573 (2013).

35. Finimundy T.C., Karkanis A., Fernandes A., Petropoulos S.A., Calhelha R. et al.: Food Chem. 327, 127043 (2020).

36. Karkanis A.C., Fernandes A., Vaz J., Petropoulos S., Georgiou E. et al.: Food Funct. 10, 1340 (2019).

37. Chen X., Shang F., Meng Y., Li L., Cui Y., et al.: J. Dairy Sci. 98, 8486 (2015).

38. Ginovyan M., Petrosyan M., Trchounian A.: BMC Complement. Altern. Med. 17, 50 (2017).

39. Kokoska L., Polesny Z., Rada V., Nepovim A., Vanek T.: J. Ethnopharmacol. 82, 51 (2002).

40. Jeppesen A.S., Soelberg J., Jäger A.K.: Afghanistan Plants. 1, 74 (2012).

41. Muttigi M.S., Kedage V., Suvarna R., Rao S.S.,

42. Joshi C., et al.: Open J. Hematol. 1, 5 (2009).

43. Prauchner C.A.: Burns 43, 471 (2017).

44. Silva J.B., De Almeida K.N., Barbosa B.B.: J. Med. Plants Stud. 5, 42 (2017).

45. Ayala A., Muńoz M.F., Argüelles S.: Oxid. Med. Cell. Longev. 1, 31 (2014).

46. Dickinson D.A., Forman H.J.: Biochem. Pharm. 64, 1019 (2002).

47. Prakash M., Shetty M.S., Tilak P., Anwar N.: Online J. Health Allied Sci. 8, 2 (2009).

48. Dasgupta A., Klein K.: Introduction to Free Radicals and the Body's Antioxidant Defense, in Antioxidants in Food, Vitamins and Supplements. pp. 1-8, Elsevier Inc, Amsterdam 2014.

48. Toufekoula C., Papadakis V., Tsaganos T., Routsi C., Orfanos S.E., et al.: Crit. Care 17, R6. (2013).

49. Demirbilek S., Ersoy M.O., Demirbilek S., Karaman A., Akin M., et al.: Intensive Care Med. 30, 1974 (2004).

50. Wang Y., Branicky R., Noë A., Hekim S.: J. Cell Biol. 217, 1915 (2018). 